\title{
Surgical treatment of early tongue squamous cell carcinoma and patient survival
}

\author{
LANSHENG ZHU $^{1}$, YANLING WANG ${ }^{1}$, RUI LI $^{2}$, AIQUN LIU ${ }^{1}$, XIAOPING ZHANG ${ }^{1}$, \\ CHUNRAN ZUO ${ }^{1}$ and XIAOTING XU ${ }^{1}$ \\ ${ }^{1}$ Department of Stomatology, Henan Province Hospital of TCM; ${ }^{2}$ Maxillofacial Surgery, \\ The First Affiliated Hospital of Zhengzhou University, Zhengzhou, Henan 450052, P.R. China
}

Received October 12, 2018; Accepted April 8, 2019

DOI: 10.3892/ol.2019.10271

\begin{abstract}
Surgical options for treating early tongue squamous cell carcinoma and patient survival were explored. Clinical records of 128 patients with early tongue squamous cell carcinoma who were treated in Henan Province Hospital of TCM from June, 2010 to June, 2013 were retrospectively analyzed. According to adopted treatment plan, the patients were divided into 3 groups: 42 patients in surgical therapy alone group, 46 patients in preoperative radiotherapy group, and 40 patients in postoperative radiotherapy group. Statistical analysis was performed on the general data of patients and clinical records, as well as the 5-year survival rate and recurrence rate. The overall 5-year survival rate for all patients was $86.7 \%(111 / 128)$, and the 5-year disease-specific survival rate was $88.8 \%(111 / 125)$. In the individual groups, the 5-year survival rate and the 5-year disease-specific survival rate were $91.3 \%$ (84/92) and $91.3 \%$ (84/92), respectively, in the surgical therapy alone group $76.9 \%(10 / 13)$ and $83.3 \%(10 / 12)$, respectively, in the preoperative radiotherapy group, and $73.9 \%(17 / 23)$ and $81.0 \%(17 / 21)$, respectively, in the postoperative radiotherapy group. There were no statistically significant differences in 5-year survival rate $\left(\chi^{2}=5.990, P=0.051\right)$ and 5-year disease-specific survival rate $\left(\chi^{2}=2.223, \mathrm{P}=0.329\right)$ among the three groups. In total, there were 25 cases of recurrence during follow-up. The recurrence rate was $19.5 \%$; the local recurrence rate was $11.7 \%(15 / 128)$; and the regional recurrence rate was $7.8 \%(10 / 128)$. There were 6 cases of metastasis, and the metastatic rate was $4.7 \%$. There were no statistically significant differences in recurrence rate and metastatic rate among the three groups. Compared with surgical therapy alone, radiotherapy combined with surgical therapy neither improved 5-year survival rate nor reduced recurrence rate. Therefore, surgical therapy alone is suggested
\end{abstract}

Correspondence to: Dr Aiqun Liu, Department of Stomatology, Henan Province Hospital of TCM, 6 Dongfeng Road, Jinshui, Zhengzhou, Henan 450002, P.R. China

E-mail: aqfqyy@163.com

Key words: early tongue squamous cell carcinoma, surgical treatment, survival to be the preferred option for treating early tongue squamous cell carcinoma.

\section{Introduction}

Tongue cancer is a common cancer in the mouth, accounting for $30-50 \%$ of all oral cancers. The most common type of tongue cancer is squamous cell carcinoma. Statistics indicated that the incidence is significantly higher for men compared to women $(1,2)$. As the population in China is aging, the incidence of tongue cancer among elderly people is increasing year by year. Because blood vessels and lymphatic vessels are rich in the tongue and the tongue muscle is frequently squeezed due to structural reasons, tongue squamous cell carcinoma is prone to metastasize even in its early stage and therefore has a poor prognosis $(3,4)$. Early diagnosis and early treatment of tongue squamous cell carcinoma is the key to patient recovery. At present, commonly used clinical treatment options for tongue squamous cell carcinoma are surgery, chemotherapy, radiotherapy and comprehensive treatment. However, therapeutic outcomes of patients with early tongue squamous cell carcinoma using various surgical protocols are still open to debate, and few related studies can be found in literature $(5,6)$. In this study, retrospective analysis was performed on clinical records of 128 patients with early tongue squamous cell carcinoma who were treated in Henan Province Hospital of TCM (Zhengzhou, China) from June, 2010 to June, 2013. Therapeutic outcomes of these patients with early tongue squamous cell carcinoma were compared between three treatment options, i.e. surgical therapy alone, preoperative radiotherapy and postoperative radiotherapy. This study aimed to provide a more precise treatment plan for patients with tongue cancer in different stages and to improve treatment.

\section{Materials and methods}

Subjects. Clinical records of 128 patients with early tongue squamous cell carcinoma who were treated in Henan Province Hospital of TCM from June, 2010 to June, 2013 were retrospectively analyzed. According to adopted treatment plan, the patients were divided into 3 groups: 92 patients in surgical therapy alone group, 13 patients in preoperative radiotherapy group, and 23 patients in postoperative radiotherapy group. 


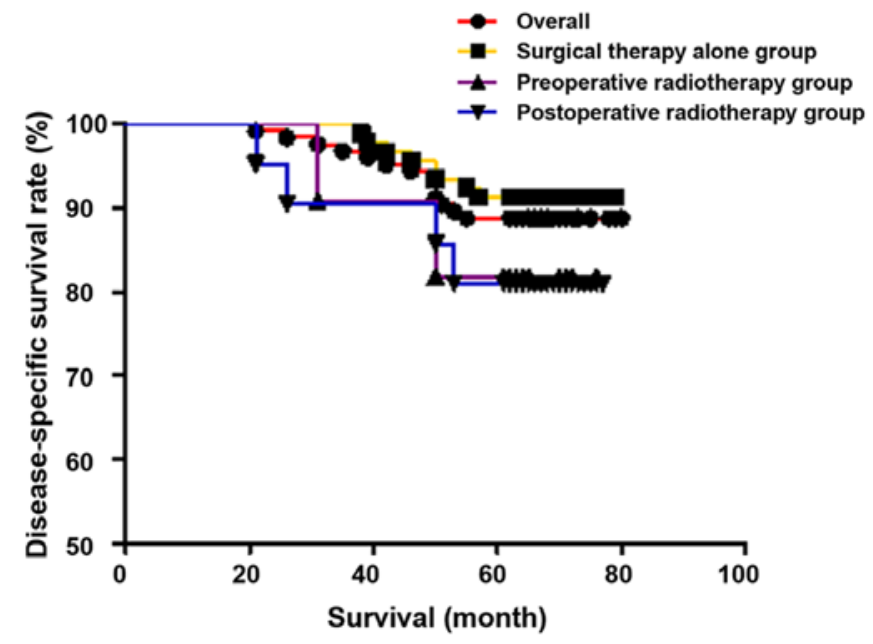

Figure 1. Disease-specific survival rates of patients in the three groups.

The study was approved by the Ethics Committee of Henan Province Hospital of TCM. Patients who participated in this research had complete clinical data. The signed informed consents were obtained from the patients or the guardians.

Inclusion criteria. Patients who met the following criteria were eligible for the study: i) Patients who were diagnosed to have primary tongue squamous cell carcinoma in the early stages (cT1-2N0); ii) patients who received treatment for the first time; iii) patients whose lesion was on the forward portion of the tongue; and iv) patients who had complete clinical records.

Exclusion criteria. Patients who met the following criteria were excluded from this study: i) patients who also had other kinds of primary cancers; ii) patients who also had lymph node metastasis; iii) patients who underwent cervical lymph node dissection; iv) patients with pathologically positive surgical margins; and v) patients who had a survival of less than two months.

Treatment procedures. Patients in the surgical therapy alone group underwent primary lesion resection, which was performed by physicians who had been in clinical practice for more than 5 years. The diseased tissue was removed along a cut edge 1-2 cm away from the lesion, resulting in cancer-free resection margins. Patients in the preoperative radiotherapy group received preoperative radiotherapy in addition to the above-mentioned primary lesion resection. First, the lesion location was determined by imaging techniques and the results of clinical diagnosis. Then, radiotherapy was given by external beam radiation alone or combination of external beam radiation and internal radiation by inserting a radiation source inside the tissue (combined radiation). The total dose of

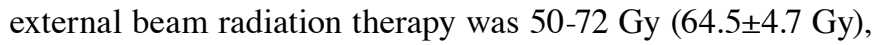
and the energy range of external radiation source was 5-6 MV. The total dose of combined radiation therapy was $<60 \mathrm{~Gy}$. Radiotherapy was completed within 15-70 days before surgery. The radiotherapy protocol in the postoperative radiotherapy group was similar to that in the preoperative radiotherapy group mentioned above. The total dose of external beam radiation therapy was 50-72 Gy $(66.1 \pm 5.3 \mathrm{~Gy})$, and the total dose

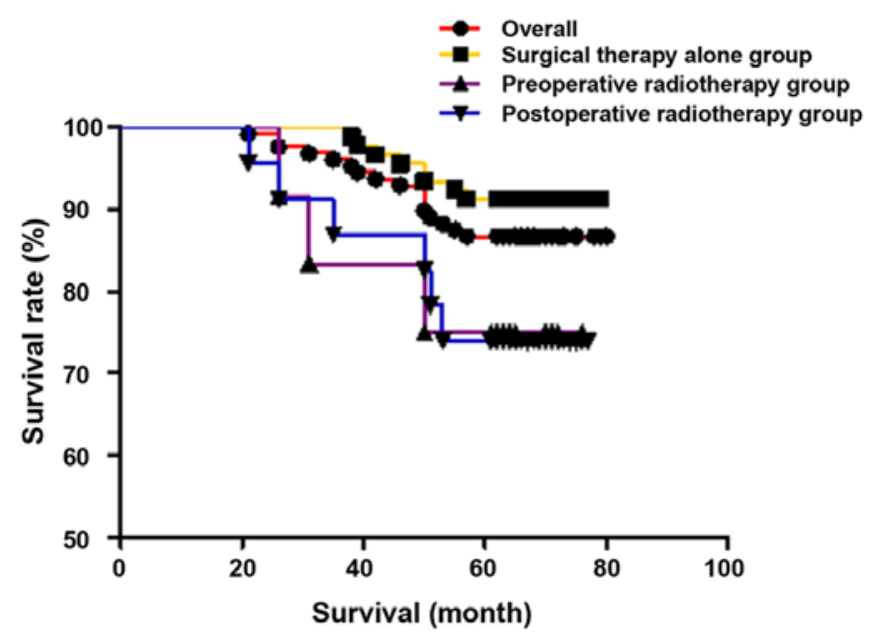

Figure 2. Survival rates of patients in the three groups.

of combined radiation therapy was $<70$ Gy. Radiotherapy was completed within 15-75 days after surgery.

Research method. Statistical analysis was performed on patient general data and clinical records, as well as the patient's 5-year survival rate and recurrence rate. The general data and clinical records included sex ratio, age distribution, disease course (referring to the time from onset to operation), pathological type, and clinical stage. The statistics of patients' clinical data were obtained by follow-up. The starting time of follow-up is the discharge time of patients, and the end time was 30 June 2018 or the death of patients. The forms of follow-up mainly include questionnaire, telephone, and outpatient follow-up.

Statistical analysis. Data were processed using SPSS 19.0 (IBM Corp., Armonk, NY, USA) statistics software. The $\chi^{2}$ test was used for comparison of quantitative data which were expressed as (mean $\pm \mathrm{SD})$. The t-test was used for comparison of measurement data. Differences in survival rate between groups were obtained by using the Kaplan-Meier test and log rant test. Results of multivariate analysis were obtained by using the COX test. A difference was considered statistically significant at $\mathrm{P}<0.05$.

\section{Results}

Comparison of patient general data. As shown in Table I, there were no statistically significant differences in sex ratio, age distribution, disease course, pathological type, clinical stage, and tumor location among the three groups.

Comparison of survival rate. The overall 5-year survival rate for all patients was $86.7 \%(111 / 128)$, that of stage I was $88.5 \%(62 / 70)$, and that of stage II was $84.5 \%(49 / 58)$. The 5-year disease-specific survival rate was $88.8 \%(111 / 125)$, which was $91.2 \%(62 / 68)$ in stage I, and $85.9 \%(49 / 57)$ in stage II. In individual groups, the 5-year survival rate and the 5-year disease-specific survival rate were $91.3 \%$ (84/92) and $91.3 \%$ (84/92), respectively, in the surgical therapy alone group $76.9 \%(10 / 13)$ and $83.3 \%(10 / 12)$, respectively, in the preoperative radiotherapy group, and $73.9 \%(17 / 23)$ and $81.0 \%(17 / 21)$, 
Table I. Comparison of patient general data.

\begin{tabular}{|c|c|c|c|c|c|}
\hline Variant & $\begin{array}{c}\text { Surgical } \\
\text { therapy alone } \\
\text { group }(n=92)\end{array}$ & $\begin{array}{l}\text { Preoperative } \\
\text { radiotherapy } \\
\text { group }(n=13)\end{array}$ & $\begin{array}{l}\text { Postoperative } \\
\text { radiotherapy } \\
\text { group }(n=23)\end{array}$ & $\chi^{2}$ & P-value \\
\hline \multicolumn{6}{|l|}{ Sex } \\
\hline Male & 56 & 8 & 15 & 0.146 & 0.929 \\
\hline Female & 36 & 5 & 8 & & \\
\hline Age (years) & $53.1 \pm 6.9$ & $55.4 \pm 7.1$ & $54.9 \pm 7.3$ & 0.663 & 0.794 \\
\hline Smoking & & & & 0.024 & 0.988 \\
\hline Yes & 51 & 7 & 13 & & \\
\hline No & 41 & 6 & 10 & & \\
\hline \multicolumn{6}{|l|}{ Disease course } \\
\hline$>6$ months & 52 & 6 & 11 & 0.903 & 0.637 \\
\hline$\leq 6$ months & 40 & 7 & 12 & & \\
\hline \multicolumn{6}{|l|}{ Pathological type } \\
\hline Well differentiated & 70 & 9 & 16 & 0.470 & 0.791 \\
\hline Moderately differentiated & 14 & 3 & 5 & & \\
\hline Poorly differentiated & 8 & 1 & 2 & & \\
\hline \multicolumn{6}{|l|}{ Clinical stage } \\
\hline Stage I & 53 & 8 & 9 & 2.787 & 0.248 \\
\hline Stage II & 39 & 5 & 14 & & \\
\hline \multicolumn{6}{|l|}{ Tumor location } \\
\hline Lateral tongue & 65 & 9 & 17 & 0.076 & 0.963 \\
\hline Ventral tongue & 21 & 3 & 4 & & \\
\hline Dorsal tongue & 6 & 1 & 2 & & \\
\hline
\end{tabular}

Table II. Comparison of recurrence rate and metastatic rate in the three groups.

\begin{tabular}{lccrr}
\hline Variant & $\begin{array}{c}\text { Surgical therapy } \\
\text { alone group }\end{array}$ & $\begin{array}{c}\text { Preoperative } \\
\text { radiotherapy group }\end{array}$ & $\begin{array}{c}\text { Postoperative } \\
\text { radiotherapy group }\end{array}$ & $\chi^{2}$ \\
\hline Patient number & 92 & 13 & 23 & 0.868 \\
Recurrence & 18 & 2 & 5 & 0.282 \\
Local recurrence & 11 & 1 & 3 & 0.225 \\
Regional recurrence & 7 & 1 & 1 & 0.087 \\
Metastasis & 3 & 1 & 0.958 \\
\hline
\end{tabular}

respectively, in the postoperative radiotherapy group. There were no statistically significant differences in 5-year survival rate $\left(\chi^{2}=5.990, \mathrm{P}=0.051\right)$ and 5-year disease-specific survival rate $\left(\chi^{2}=2.223, \mathrm{P}=0.329\right)$ among the three groups. The results are shown in Figs. 1 and 2.

Comparison of recurrence rate and metastatic rate in the three groups. As shown in Table II, there were 25 cases of recurrence in total during follow-up. The recurrence rate was $19.5 \%$; the local recurrence rate was $11.7 \%(15 / 128)$; and the regional recurrence rate was $7.8 \%(10 / 128)$. There were 5 cases of metastasis, and the metastatic rate was $4.7 \%$. There were no statistically significant differences in recurrence rate and metastatic rate among the three groups.

\section{Discussion}

Surgical therapy is the primary treatment option for tongue cancer, while radiotherapy and chemotherapy are adjuvant therapy. Patients rarely receive radiotherapy or chemotherapy alone for tongue cancer. Radiotherapy and chemotherapy have proven systemic toxic side effects, and physicians are unable to reach a consensus on whether they have an impact on patient survival $(7,8)$. All the subjects in this study underwent surgical treatment and included the majority of patients diagnosed with tongue squamous cell carcinoma. This study aimed to provide a scientific reference for the treatment of tongue cancer.

Patients with tongue cancer have a poor prognosis. The 5 -year survival rate is about $27 \%$ for mid-stage/late stage 
patients. The subjects included in this study were all patients with early tongue squamous cell carcinoma, for whom few research reports appear in literature. In this study, the overall 5 -year survival rate and the 5-year disease-specific survival rate were 86.7 and $88.8 \%$, respectively, which were all higher compared with similar studies in literature $(9,10)$. The causes of this exceptional result could be that i) the patients selected in this study had milder symptoms or ii) continuous advancement of medical technology led to overall improvement of treatment outcomes such as overall survival rate of patients with early tongue squamous cell carcinoma $(11,12)$. There were no statistically significant differences in 5-year survival rate among patients in the three groups. To get more accurate results, a larger sample size may be needed because the number of subjects in this study reached the threshold. However, some studies have pointed out that (13) functional and aesthetic deficiencies caused by radical surgery can reduce the quality of life of patients, so conservative treatment is better than radical treatment for elderly patients aged over 60 years. Therefore, the average age of patients selected into this study is lower than 60 years.

The main purpose of preoperative radiotherapy was to attenuate tumor cell activity and reduce the risk of tumor cell implantation into benign lesions, thereby lowering cancer recurrence rate and metastatic rate. In addition, preoperative radiotherapy can significantly decrease tumor cell volume, making the surgical procedures a little easier to perform. The postoperative radiotherapy was to give patients more precise radiotherapy in terms of location and dose because related information can be more accurately obtained after surgery and verified using imaging techniques. Postoperative radiotherapy was expected to improve the treatment $(13,14)$. In this study, it was found that adjuvant radiotherapy did not improve the 5 -year survival rate of patients with early tongue cancer. Our finding was opposite to reports in literature $(15,16)$, and the possible reason could be that the recruited patients with early tongue cancer had relatively milder symptoms. Surgery caused great tissue injury to the patient's body. In addition, systemic side effects of radiotherapy can seriously affect the immune system. Surgical therapy alone would be enough to achieve the treatment goal. In order to avoid overtreatment and reduce complexity of treatment procedures, the authors suggest that surgical therapy alone be adopted to treat patients with early tongue squamous cell carcinoma.

There were 25 cases of recurrence in total during follow-up. The recurrence rate was $19.5 \%$; the local recurrence rate was $11.7 \%(15 / 128)$; and the regional recurrence rate was $7.8 \%(10 / 128)$. There were 6 cases of metastasis, and the metastatic rate was $4.7 \%$. It was found that neither preoperative radiotherapy nor postoperative radiotherapy can reduce the 5 -year recurrence rate. The possible reason could be that both preoperative radiotherapy and postoperative radiotherapy had a balance between effectiveness in killing cancer cells and aggressiveness in causing damage to the body (17-19). Radiotherapy caused great damage to the patient's body, and was probably too aggressive for treating early tongue squamous cell carcinoma. Preoperative and postoperative radiotherapy should be avoided as much as possible.

In conclusion, compared with surgical therapy alone, radiotherapy combined with surgical therapy neither improved 5 -year survival rate nor reduced recurrence rate. Therefore, surgical therapy alone is suggested to be the preferred option for treating patients with early tongue squamous cell carcinoma.

\section{Acknowledgements}

Not applicable.

\section{Funding}

This study was supported by 2016 Henan Science andTechnology Research Program Fund Project (162102310183).

\section{Availability of data and materials}

The datasets used and/or analyzed during the present study are available from the corresponding author on reasonable request.

\section{Authors' contributions}

$\mathrm{LZ}$ and $\mathrm{YW}$ worked on treatment procedures. AL and RL collected and analyzed general data and clinical records. XZ and $\mathrm{CZ}$ were responsible for patient's 5-year survival rate and recurrence rate analysis. LZ and XX contributed to statistical analysis. LZ wrote the manuscript. All the authors read and approved the final manuscript.

\section{Ethics approval and consent to participate}

The study was approved by the Ethics Committee of Henan Province Hospital of TCM (Zhengzhou, China). Patients who participated in this research had complete clinical data. The signed informed consents were obtained from the patients or the guardians.

\section{Patient consent for publication}

Not applicable.

\section{Competing interests}

The authors declare that they have no competing interests.

\section{References}

1. Kelner N, Rodrigues PC, Bufalino A, Fonseca FP, Santos-Silva AR, Miguel MC, Pinto CA, Leme AF, Graner E, Salo T, et al: Activin A immunoexpression as predictor of occult lymph node metastasis and overall survival in oral tongue squamous cell carcinoma. Head Neck 37: 479-486, 2015.

2. Aparna M, Rao L, Kunhikatta V and Radhakrishnan R: The role of MMP-2 and MMP-9 as prognostic markers in the early stages of tongue squamous cell carcinoma. J Oral Pathol Med 44: 345-352, 2015.

3. Maxwell JH, Thompson LD, Brandwein-Gensler MS, Weiss BG, Canis M, Purgina B, Prabhu AV, Lai C, Shuai Y, Carroll WR, et al: Early oral tongue squamous cell carcinoma: Sampling of margins from tumor bed and worse local control. JAMA Otolaryngol Head Neck Surg 141: 1104-1110, 2015.

4. Thiagarajan S, Nair S, Nair D, Chaturvedi P, Kane SV, Agarwal JP and D'Cruz AK: Predictors of prognosis for squamous cell carcinoma of oral tongue. J Surg Oncol 109: 639-644, 2014.

5. Ren ZH, Wu HJ, Zhang S, Wang K, Gong ZJ, He ZJ and Peng J: A new surgical strategy for treatment of tongue squamous cell carcinoma based on anatomic study with preliminary clinical evaluation. J Craniomaxillofac Surg 43: 1577-1582, 2015. 
6. Janakiraman H, House RP, Talwar S, Courtney SM, Hazard ES Hardiman G, Mehrotra S, Howe PH, Gangaraju V and Palanisamy V: Repression of caspase-3 and RNA-binding protein HuR cleavage by cyclooxygenase-2 promotes drug resistance in oral squamous cell carcinoma. Oncogene 36: 3137-3148, 2017.

7. Abu-Ghanem S, Yehuda M, Carmel NN, Leshno M, Abergel A Gutfeld $\mathrm{O}$ and Fliss DM: Elective neck dissection vs observation in early-stage squamous cell carcinoma of the oral tongue with no clinically apparent lymph node metastasis in the neck: A systematic review and meta-analysis. JAMA Otolaryngol Head Neck Surg 142: 857-865, 2016.

8. Tsushima N, Sakashita T, Homma A, Hatakeyama H, Kano S, Mizumachi T, Kakizaki T, Suzuki T and Fukuda S: The role of prophylactic neck dissection and tumor thickness evaluation for patients with cNO tongue squamous cell carcinoma. Eur Arch Otorhinolaryngol 273: 3987-3992, 2016.

9. Goepfert RP, Kezirian EJ and Wang SJ: Oral tongue squamous cell carcinoma in young women: A matched comparison - do outcomes justify treatment intensity? ISRN Otolaryngol 2014: 529395, 2014.

10. Tong XJ, Tang ZG, Shan ZF and Guo XC: The anterolateral thigh flap for soft tissue reconstruction in patients with tongue squamous cell carcinoma. World J Surg Oncol 14: 213, 2016.

11. Goto M, Hanai N, Ozawa T, Hirakawa H, Suzuki H, Hyodo I, Kodaira T, Ogawa T, Fujimoto Y, Terada A, et al: Prognostic factors and outcomes for salvage surgery in patients with recurrent squamous cell carcinoma of the tongue. Asia Pac J Clin Oncol 12: e141-e148, 2016.

12. Cohen EE, Karrison TG, Kocherginsky M, Mueller J, Egan R, Huang $\mathrm{CH}$, Brockstein BE, Agulnik MB, Mittal BB, Yunus F, et al: Phase III randomized trial of induction chemotherapy in patients with N2 or N3 locally advanced head and neck cancer. JClin Oncol 32: 2735-2743, 2014.

13. Zhang P, Zhang L, Liu H, Zhao L, Li Y, Shen JX, Liu Q, Liu MZ and $\mathrm{Xi}$ M: Clinicopathologic characteristics and prognosis of tongue squamous cell carcinoma in patients with and without a history of radiation for nasopharyngeal carcinoma: A matched Case-Control Study. Cancer Res Treat 49: 695-705, 2017.
14. Sung KW, Kim SM, Myoung H, Kim MJ and Lee JH: The effectiveness of elective neck dissection on early (stage I, II) squamous cell carcinoma of the oral tongue. J Korean Assoc Oral Maxillofac Surg 43: 147-151, 2017.

15. Toporcov TN, Znaor A, Zhang ZF, Yu GP, Winn DM, Wei Q, Vilensky M, Vaughan T, Thomson P, Talamini R, et al: Risk factors for head and neck cancer in young adults: A pooled analysis in the INHANCE consortium. Int J Epidemiol 44: 169-185, 2015.

16. Meng J, Gu QP, Meng QF, Zhang J, Li ZP, Si YM, Guo W and Zhuang QW: Efficacy of nimotuzumab combined with docetaxel-cisplatin-fluorouracil regimen in treatment of advanced oral carcinoma. Cell Biochem Biophys 68: 181-184, 2014.

17. Katz O, Nachalon Y, Hilly O, Shpitzer T, Bachar G, Limon D and Popovtzer A: Radiotherapy in early-stage tongue squamous cell carcinoma with minor adverse features. Head Neck 39: 147-150, 2017.

18. Wu K, Li S and Zhang C: Lymph node transfer characteristics and clinical assessment and treatment of early tongue squamous cell carcinoma. Int J Stomatology 42: 30-47, 2015.

19. Hakeem AH, Pradhan SA, Kannan R and Tubachi J: Clinical outcome of surgical treatment of T1-2 N0 squamous cell carcinoma of oral tongue with observation for the neck: Analysis of 176 cases. Ann Maxillofac Surg 6: 235-240, 2016.

(i) (9) This work is licensed under a Creative Commons Attribution-NonCommercial-NoDerivatives 4.0 International (CC BY-NC-ND 4.0) License. 